\title{
Risk Information Management in Support of UN Humanitarian Missions
}

\author{
Horst Kremers \\ CODATA-Germany,office@horst-kremers.de
}

Keywords: Humanitarian Support, Risk Information Mangement, United Nations, Applied Informatics, Digital Semiotics, Data Spaces, Information Governance

\begin{abstract}
:
The UN Declarations and other UN Instruments texts increasingly enforce the demands for coherence and mutual synergies. This paper describes the basic elements of coherence, consequences for holistic information management across programs and conventions and rises awareness on key issues in information governance needed to foster crossdomain and cross-organizational national as well as international implementations needed to grant timeliness support of societal, natural, technical, humanistic and ethical aspects for the future of people and planet.

The requirements for coherence are defined in the texts of the core and neighboring UN Instruments (Transnational Declarations, Conventions, Treaties, Frameworks and Directives) : UN HABITAT, UN Sustainable Development Goals SDGs, UNDRR Sendai Framework on Disaster Risk Reduction, UN Framework Convention on Climate Change, International Platform on Biodiversity and Ecosystem Services IPBES, Human Rights, Children Rights, IPCC, UNDP, UN World Food Program, and many others.
\end{abstract}

On the operational level, syntactic, semantic and pragmatic coherence (full semiotics coherence, that comprizes syntax, semantics and pragmatics domains) needs to be achieved on local, regional, national and international levels.

This presentation will address Information Management issues based on extensive best management principles.

- Complexity Challenges

- Pragmatics Models

- Information Modeling and Analytics

- Algebraic Properties of Data Spaces

- Information Governance

Finally, recommendations for action as well as consequences for R\&D in the fields of Cartography as a Data Science are given. 